\title{
Sonic Diegesis: Reality and the Expressive Potential of Sound in Narrative Film
}

\begin{abstract}
Perspectives and approaches from electroacoustic music are applied to support a phenomenological understanding of the role of sound in film, whereby all sounds are presented as potential drivers of cinematic diegesis.

Building upon notions of the non-diegetic fallacy (Winters 2010, Kassabian 2008) and extending these concepts from film music into an examination of all sound, conventional classifications of sound into binary (diegetic / non-diegetic) and tripartite (Voice / Music / Sound Effects) divisions are challenged. Such divisions are argued as limiting to an understanding of the full expressive potentials of sound, failing to reflect the filmic experience, by assigning limited functional roles to specific types of sound.

Notions of "reality" are core to this exposition, with existing analytical distinctions operating in relation to an assumed objective reality, a transparent mimesis, which fails to take into consideration the subjectivity of the audience nor the diegetic potential of mimetic sounds. However, with reference to specific examples drawn from mainstream cinema - Gravity [20I3], Dunkirk [2017] - and creative practice research - coccolith [2016] - the expressive potential of sound is demonstrated to be embodied by all sound types, with the apparent realism of mimetic sounds belying their significant diegetic power. Indeed, the illusory realism of mimetic sounds is argued as core to their communicative action and affect, extending audiences' own experiences of sonic phenomena.

Approaches to the analysis of sound within narrative film contexts are demonstrated and posited as affording deeper and more nuanced readings of the role of all sound in the construction of filmic diegesis.
\end{abstract}

\section{Key Words}

Sound, Film, Diegesis, Mimesis, Realism, Naturalism, Narrative, Gravity, Dunkirk, coccolith, 


\section{Electroacoustic Music: The Concrète and the Anecdotal}

Just as early film developed as an art of visually recorded movement, pioneers and composers seized the possibilities of recorded sound to develop new forms of musical expression, an art of organised sounds.

Musique Concrète emerged from the studios at Radio France from 1948, where Pierre Schaeffer - a violinist and studio practitioner - developed experiments that identified the rich potential for musical manipulation and composition with recorded sound. These early experiments explored the musical opportunities in manipulating recorded sound - looping, reversing, transposing and splicing - and in concert Schaeffer began the process of formalising these new possibilities in what would become his Traité des objets musicaux (Schaeffer 1966).' One of the key ideas of his thesis was the identification of the way in which we could listen to the same sounds in different ways:

- Listening [Écouter] - listening to identify the source, the event, the cause. Treating the sound as a sign of this source. (E.g. I hear an ambulance).

- Perceiving [Ouir] - being aware of sounds that are around you, but without focussing on or seeking to understand them. (E.g. being vaguely aware of sirens and traffic noise as part of a general city soundscape).

- Hearing [Entendre] - directed listening towards specific parameters of a sound. (E.g. focussing on the pitch / timbre / duration or intensity of the siren).

- Comprehending [Comprendre] - grasping a meaning, treating the sound as a sign, referring this meaning through a language or a code. (E.g. there has been an accident or emergency) (adapted from Chion 2012, p.19-20)

These modes are not absolute, the listener may shift between each according to their "listening intention". Thus, Schaeffer recognised that "[the] sound object is the meeting point of an acoustic action and a listening intention" (Chion 2009, p. 27). The goal of Musique Concrète was to encourage Entendre, for sounds to escape their source bond and to be experienced independently of the source that created them. This state of reduced listening freed sounds from the denotive, allowing them to be heard affectively and not as a descriptive signifier for their source cause:

\footnotetext{
I There are many sources that eloquently elaborate the history and development of this artform and other arts of sound including: Manning 2004; Landy 2010; Schaeffer 2012, Chion 2010.
} 
"every sound phenomenon [...] can be taken for its relative meaning or for its own substance. As long as meaning predominates, and is the main focus, we have literature and not music" (Schaeffer 2012: 13).

Earlier experiments in montage with recorded sound, such as Walther Ruttmann's Wochenende, remain within, and indeed rely upon, literary notions of descriptive narrative and direct association of sound with source cause. ${ }^{2}$ The innovation of Musique Concrète was to realise the Futurist dream of a music made from the infinite variety of noise-sounds (Russolo in Cox and Warner 2004 :I I). "I needed to tear noise away from its dramatic context [...] before giving it form. If I succeeded there would be concrete music. If not, there would be nothing but stage and radio sound effects." (Schaeffer 2012: 38)

In much the same way that the early pioneers of film forewarned of the potential dangers of synchronous sound in sound film ${ }^{3}$, Schaeffer rejected the use of sound as a mere signifier of source cause, instead seeking to realise the material and musical potentials of sound. But in the 1960s, Luc Ferrari famously rebelled against the strict ideological standpoint of Schaeffer's GRM, daring to include fragmented shots of the "real world" within what he termed to be anecdotal music compositions (Emmerson 2007: 7).
"I thought it had to be possible to retain absolutely the structural qualities
of the old musique concrète without throwing out the reality content of the material which it had already. It had to be possible to make music and to bring into relation the shreds of reality in order to tell stories" (Ferrari in Emmerson 2007: 7 [original emphasis]).

Ferrari sought to reintroduce a dualism to the listening experience, to shift audiences between different modes of listening, drawing their appreciation of reduced sounds into the contexts of the real and to play with the denotive power of sounds. This trajectory was further developed by later proponents of soundscape composition (such as R Murray Schaffer \& Hildegard Westerkamp) adopting extended location sound recordings as a key compositional material. Though recognisable, these location sounds were often employed with the intention of extending beyond the real; as Tim Ingold highlights:

\footnotetext{
${ }^{2}$ As Julio d'Escriván notes, some techniques that might be considered proto-electroacoustic can be found in even the earliest of sound films (d'Escrivan 2007) and Andy Birtwistle highlights how the creative use of sound was conceptualised by filmmakers in the British Documentary tradition, in very similar terms to that of the early proponents of new music (Birtwistle 2016: 392).

${ }^{3}$ For example, Eisenstein, Pudovkin \& Alexandrov in their famous Statement.
} 
"[Soundscape composition's] purpose is not to represent but to reveal, to penetrate beneath the surface of things so as to reach deeper levels of knowledge and understanding" (Ingold 2000: I30).

The use of real world materials in soundscape composition are designed to evoke affective responses to heard sounds, not to replicate objective "real" soundscapes but to inspire the listener's imagination and association. Within this process soundscapes are often extended or transformed to highlight processes of change and to draw attention to the malleable nature of listening. Thus, the potentials of abstract musique concrète are expanded and merged with the potentials of the recognisable to create creative treatments of naturalistic soundscapes. ${ }^{4}$

Within the context of film, sounds are often similarly chosen applied for the impression that they render as opposed to the actual realities of the real world. ${ }^{5}$ The presence of the visual frame in cinema offers a counterpoint against which all sounds can play, interact and ascribe agency. However, while conventional sound design approaches embrace the malleability of sound to convey impressions and connote, they are often poorly represented by the largely literary or linguistic frameworks which are often used to interpret and describe sound in narrative film.

Film sound is too often compartmentalised into discrete components (i.e. voice, music, sound effects) and considered in terms of semiotic agency, directed by linguistic norms which seek to identify explicit and quantifiable units of meaning without fully understanding the nuances and subtleties possible in communication through diverse listening modes. As Andy Birtwistle asserts, "approaching film and video sound through the concept of signification [...] rather too neatly coincides with the way in which we casually formulate sounds in terms of the objects or events perceived as their source, describing sonic phenomenon as the sound of something or other" (2010: 5). Within this context sounds can never just be; they must always be something. And as such they are denied the opportunity to reveal their full potential.

\section{Between Worlds - Reality and diegesis}

Film does not replicate reality, even Sound Design effects - which might conservatively be considered mimetic elements of realism - are never so simply deployed. The creative processes which capture, generate and modulate sonic materials in film are all undertaken with intent to encourage audience interpretations that are specific to scenes, characters, locations and story

\footnotetext{
${ }^{4}$ For a detailed exposition see the authors paper, Hill 2017.

${ }^{5}$ Within this paper Sound Design is used to refer to the creation and editing of spot effects and atmospheric "wild tracks", employed to construct the "real" world of the film. Musical underscore or is used to refer to compositions developed that accompany narrative sequences.
} 
arcs. For example, when a door closes either a "k-tuk", or a "g-thunk" sound could articulate the visual action. The contrasting qualities of each sound results in a different impression being projected into the scene, with the material properties of the sound indivisible from the affect that they create. By recognising the multiplicity of listening intentions, such as those outlined by Schaeffer above, it is possible to appreciate how sound conveys impressions in a variety of ways. Even if consciously recognised by the audience through Éntendre as "the sound of the door" (or unconsidered as Ouir a background sound) the qualities of the door sound will convey different impressions, through Comprendre, acting as implicit signifiers of the door as either light, fragile and brittle ("k-tuk") or heavy, solid and strong ("g-thunk"). These different sounds may contribute to the construction of very different interpretations of the same scene, the sounds of the door may project its own sonic characteristics onto the character who opens and closes it. A mainstream Hollywood example can be found in the gunshot sound that rings out from Indiana Jones' revolver in Raiders of the Lost Ark. This sound is actually the unprocessed report of a large calibre rifle, affording gravitas and power to the hero, in contrast to the lighter and higher frequency report of the weapons possessed by the rival 'bad guys' (Bouzereau 2003). This decision within the design of the character's sound forms a key part of the films identity, as important as the characters hat, whip or theme music. This is not just a gunshot, but a clear act of narrative storytelling, a distinct creative choice which pulls at the reins of reality to form the film's diegesis. As Michel Chion notes, "Cinema [...is] an art of the simulacrum" (2010: xi).

Sound design for the 2013 film Gravity took inspiration from the "real world" condition of tactile sound transmission in space, a point highlighted by the film's opening titles which state: "There is nothing to carry sound" (Figure I. Gravity [2013] Opening Titles). But this mimetic façade obscures the reality of the final soundtrack's constructed nature. The sound effects were themselves designed and composed in such a way to extend them from simple mimesis into musicality, with Glenn Freemantle's rhythms of clanks, whirs and crunches merging seamlessly into the rhythms and tones of the electronic score by Steven Price. The musical underscore, in turn, performs a large number of sonic roles that would usually be carried by sound effects, for example: within Clip One (Film Clip I. Gravity [20I8]) glissandi accompany the trapped spaceship as it flings itself about wildly while still tethered to the space station [0:00-0:12 \& 0:15-0:40]. These sounds approximate the classic aeroplane "dive" sound which would usually accompany a crashing or rapidly descending aircraft, implying rapid descent and impending collision. This musical gesture is punctuated by drums and a filtered percussive thump when the craft reaches the end of its tether [0:07]. These function as an interjection into the steady build-up, imposing an impression of time 
upon the smooth glissandi. The timbre of this thump invokes a mimetic association established earlier in the film, with its timbre akin to the filtered structure-borne sounds heard accompanying the astronauts through their space suits in the opening scenes. However, the audience's point of view at this point [0:07] rests not with one of the characters, but external to the spaceship in the void of space, and thus in "realistic" mimetic terms there should be no sound. 6 The implied mimetic thump sounds are complemented by musical drums in the construction of a dramatic arc, with these percussive sounds moving into phase with each other. Beginning out of alignment these sounds come into perfect sync to articulate the point of maximum intensity [0:20], at which the spaceship reaches the end of its tether. The very process of these sounds moving into phase with one another physically embodies the notion of distinct parts coming together and sets up an expectation in the mind of the audience that they will always be associated. This synchronous hit emphasises the moment of impact and ties these two sounds together. In the section that follows the drums continue, occurring around the point at which the spaceship almost collides with the space station [0:32] but without any mimetic counterpart, thus drawing out the tension inherent in the counterpoint between these rhythmic sounds, subverting the expectation constructed earlier in the clip by failing to resolve the synchronous impact of the mimetic thumps and the drums.

Other key elements in this scene are the short granular noise bursts which are applied as pointillistic texture over the top of the smooth glissandi. These noise textures are initially heard at the same time as the pilot engages her thrusters within the cabin - with the white flashes of VFX representing compressed air thrusters - but the visual actions soon become detached from the granular textures through lack of explicit sync. ${ }^{7}$ The granular sounds begin as mimetic gestures but rapidly transition into dramatic drivers of narrative, enhancing the intensity of the scene through their high tempo, instability and their amplitude profile. As the point of potential collision is approached these granular sounds crescendo rapidly [0:28-0:32], projecting a forward trajectory which contributes towards the sense of climax, transitioning across the cut to be heard in the void of space (again subverting the realist mimetic allusion). When these granular sounds do indeed disappear they create a space pregnant with anticipation for an almighty metallic crash of collision. This absence, a sonic intake of breath, remains unresolved, being instead pricked only by

\footnotetext{
${ }^{6}$ That the point of view and point of audition do not always coincide is also demonstrated plainly by the fact that we hear a voice at the opening of this example clip expressing dismay "no, no, no" as we view the spaceship from an external perspective [0:00-0:02].

${ }^{7}$ The acoustic environment within which these sounds exist is also quite distinct from all other sounds in the sequence, they are incredibly dry, lacking in the reverberation of the spaceship cabin or that which accompanies the glissandi and tones. We will return to explore this in more detail below.
} 
the light, almost rubber band-esque, "t-ping" sound at [0:34] which articulates the bending of the aerial/antenna. Once the moment of crisis has passed they return to their mimetic role [0:40$0: 49]$, soon underscored by a low frequency creaking groan that releases tension built up through the preceding sequence and never resolved, a sonic sigh of relief.

Here then, the sounds within the mix occupy a unified sonic space, operating as a holistic composition taking on both mimetic and expressive roles. The sounds do not simply elaborate and flesh out the implied world of the film. The material characteristics of the sounds lend themselves to the diegesis, with the unity of sound effect and musical underscore constructing the diegetic world of the film and driving the narrative discourse. Naturalistic inspiration affords novel approaches to the interrelationship between the layers of sound, within which narrative roles are transposed and shared. Both sound and musical underscore are indissoluble from one another in articulating the final aesthetic result. Mimetic sounds are orchestrated just as the tones, glissandi and percussion are, their fluid counterpoint weaving the diegesis.

\section{Musical Underscore and Diegesis - Shifting Tones}

In stark contrast to sound effects, musical underscores, are traditionally theorised as distanced from the material world of the film. Ascribed to their own separate narrative plane from which they provide commentary upon the visual actions of the film: "The music of a film follows a narrative track, like the events of a story but it also tends to take on a life or identify of its own, like a discourse that frames the story" (Goldmark, Kramer, Leppert 2007: 3). This distancing allows musical underscores to be accepted as abstract conveyers of meaning and emotion, performing an affective role free of any source bond. But such distancing onto a separate narrative plane betrays how even the communicative role of musical underscores are so often framed within semantic and linguistic terms. When conceptualized in a logocentric fashion, music is denied its materiality, becoming read as a layer of abstract signification pointing towards visual action. It is separated so far from the action that it is considered as providing an almost independent stream/ layer of information that the audience negotiates in parallel to interpret meanings from the film. Such a structuralist division does not reflect contemporary understandings of interpretation and experience, within which sensory information is interpreted more holistically (for example: Clarke \& Clarke 201I; Cox 2016; Coëgnarts \& Kravanja 20I5). Nor does it account for the musical articulation of specific on-screen actions, gestures which articulate or foreshadow explicit onscreen action, such as those described above in the example from Gravity. 
In his paper on the Non-diegetic fallacy Ben Winters argues that Claudia Gorbman's misapplication of narratological concepts as a basis for her discussion of film music construct a false dichotomy, he writes: "to assume that music functions primarily as a narrating voice in a narratological sense, rather than as an indicator and occupier of narrative space, is perhaps to misunderstand the broader nature of cinematic diegesis" (Winters 2010, p.225). Just as with sound effect, the musical underscore performs a complex and multifaceted role in conveying the meaning in film. This shift between music operating as indicator to instead becoming occupier is key. An example can be found in the underscore within Christopher Nolan's film Dunkirk (2017). The music does not merely comment upon or respond to the visual, but acts as a key element within the construction of the overall aesthetic experience. It acts to fulfil three interrelated roles:

\section{Representing unseen protagonists.}

The underscore represents the film's major acousmatic protagonist: the advancing enemy troops. The underscore's frequent foregrounded nature and wide spectral range convey the impression of an expansive and very present threat. Extended glissandi linger over the onscreen action, building in threatening intensity whenever the unseen enemy projects its influence into the film. These tones are echoed by the pitches within the diving aircraft engines and thus the offscreen acousmatic enemy is later linked by association to its onscreen counterpart. The textures and gestural forms that constitute the timbre of this acousmatic threat evolve over the course of the film, increasing in spectral density and timbral richness through each recurrence. As they do so, they act to imply the increasing presence and ever threatening advance of the off-screen enemy.

\section{Embodying affective intensity through texture and gestural motion.}

The timbral evolutions deployed, drive the affective intensity of the audience's experience. Increases in pitch, density, loudness are common musical tools for driving filmic intensity, applying their materiality to convey tactile affects to the listener. But, as highlighted above (in discussion of the examples of the closing door and Indiana Jones' gun), sounds do not represent ideas apart from themselves, they are the embodiment of ideas. As Anahid Kassabian highlights, the roles and actions of film sound, are intimate, somatic, haptic (Kassabian 2007), operating as Katherine Norman describes through a "timbre of experience" (Norman 1994: 107).

In opposition to structuralist conceptions of language dependent upon an abstraction between material and content (and the notion of parallel non-diegetic signifying music), 
this interpretation recognizes that the very power of much audiovisual content lies within its material embodiment of concepts. ${ }^{8}$

3. Providing trajectory and form to the film.

With sound muted, the slow panning shots across the beach, or the cuts to aeroplanes and boats become dislocated, there are no markers against which these disparate montages can be orientated. With divergent temporality between the three main narratives, the perspectival shift operates in both time and space. The images possess none of the structural clarity of the audiovisual whole, and when silent the film's urgent and coherent trajectory is lost. The soundtrack provides grounding themes against which the narratives can be interpreted, with recurring sonic motifs and gestures providing forms which narrate the visual action.

The recurring feature of the ticking watch is one such example, introduced in the opening scene it morphs into, or is reflected by, the underscore. Its tempo modulates to drive the trajectory of the film, enhanced at points with timbral changes and the use of Risset acellerandos. ${ }^{9}$

Another example can be found with the attacking dive bombers that return again and again in the film, their appearance is always prefigured by a dramatic anacrusis and low frequency "whoosh" gesture which announces their dramatic presence. This sonic gesture is what Smith describes as an act of "intensified sonic continuity" acting to highlight the self-consciousness of the films narration (Smith 2013: 345/338). In such a context the underscore constructs diegetic unity, tying together the various mimetic vignettes, standing in as one of the key players in the films narrative while the visual tends towards the mimetic, showing.

These three interrelated functions of the music within Dunkirk are thus demonstrated to be intrinsic to the films structure and communicative potential. Of course, the creative challenge of the film's narrative is to construct a dramatic discourse around waiting. The characters have nowhere to go, stuck visually in a limited fixed location surrounded by a (largely) unseen enemy. The acousmatic musical underscore is the only filmic element that has the real freedom to move and it does so in counterpoint to these (largely) static images. ${ }^{10}$ The music in this film cannot be

\footnotetext{
${ }^{8}$ In Dunkirk the mimetic sound effects of explosions and creaking metal embody the impressions of the physical spaces and materials of the filmic world, even while the foregrounded underscore is the primary driver of the narrative.

${ }^{9}$ See Stowell 2011 for details about this psychoacoustic effect.

${ }^{10}$ Even the story arcs with aeroplanes and boats (objects which might be considered as possessing movement) lack a sense of forward progression due to the lack of fixed reference points within the open expanses of sky and water.
} 
relegated to be described as a non-diegetic element, because it constitutes a key component of the film's own diegesis driving structure and effective experience. There is no narrative parallelism, but a unity of sound with image.

In Gravity and Dunkirk, each sound exists as part of the constructed world of the film, from the mimetic "real world" to the abstract "musical", each sonic element contributes to the construction of the diegesis. All of these sounds operate in sympathy with one another, contextualizing themselves, and the image, within the construction of an audiovisual space, what Nicholas Reyland describes as a "musically mediated narrative structure" (Reyland 2012: 69). To understand such a complex networked situation a holistic perspective is the most vital. The traditional distinctions of diegetic and non-diegetic are unable to perform in this context, limited as they are by fixation upon the identification of an apparent implied source as its key qualifying feature. However, if it is conceded that all sounds construct the diegesis, then a binary distinction, whether something is diegetic or not, is no longer appropriate. The definition must untangle itself from the question of mimesis (reality versus abstraction) and implied source bonding within the internal world of the film, and move instead towards describing the way in which sonic (and other filmic) elements contribute to the overall articulation of narrative (diegesis - narrative that tells).

\section{Who's Reality? - Mimetic / Diegetic}

As Winters highlights the very term diegetic is applied inconsistently to film. He highlights the distinction between the Platonic definition of "telling" and the stratified literary definition derived from Gérard Genette in which different narrative voices operate at various levels of literary diegesis (Winters 2010: 225). The former embraces all elements of the film into a unified narrative construction, while the later compartmentalises and separates into discrete parallel components. Both Winters and Kassabian argue that this separation from the space of the narrative masks the role that music plays within the construction of the diegesis (Winters 2010: 224) (Kassabian 200I: 42).

As is inevitable, a method of literary analysis applied to sound and music reveals its own bias within the result. As Winters states, 'music's description in film as 'non-diegetic' is both overly reliant on the concept's narratological meaning, and representative of an unwillingness to recognize film's inherent 'unreality"' (Winters 20I0: 224). In the Platonic definition, diegesis is clearly distinguished from mimesis; telling as distinct from showing. However, this distinction is lost within Claudia Gorbman's use of the term diegetic, with music defined as that which "issues from a source within the narrative" (Gorbman 1987: 22). In fixating on source cause, Gorbman merges the mimetic and the diegetic applying the logic of reality to the unreality of film. 
Robynn Stilwell, Jerrold Levinson and James Wizerzbicki have all sought to provide alternative terminologies and frameworks to better describe the action of sound within film, and yet they all do so by defining sounds in relation to an assumed objective reality. Stilwell describes sounds as being either objective or subjective (Stilwel 2007: 190); Levinson uses the terms additive or narrative" " while Wizerzbicki talks of effects and affects. ${ }^{12}$ Each therefore, suggest that sounds can be either mimetic (descriptive) or diegetic (instructive).

But such descriptions imply that mimesis is transparent (a true reality) while the sounds that tell stories and drive narrative or meaning are those which are unreal in some sense. As demonstrated above, this is a fallacy. Every image and every sound brought together within a film are imbued with an expressive potential by virtue of their combination and character. Even works filled with entirely mimetic materials, are not concerned with replicating some pure duplication of reality. As Katherine Norman explains in discussion of 'real-world music', the process of composition with mimetic materials is, despite its name, "not concerned with realism, and cannot be concerned with realism since it seeks, instead, to initiate a journey which takes us away from our preconceptions, so that we might arrive at a changed, perhaps expanded, appreciation of reality" (Norman 1996: 19). Therefore, while the mimetic properties of both of these materials might initially suggest a passive display of the real, there is always a creative decision process that modulates these into being - a form of told diegesis.

Even the most mundane sound can be imbued with significance within the discourse of a filmic narrative, all sounds are defined through their relationships to one another, indeed the definition of the role of any sound within the discourse will be inherently dependent upon the action and roles of the other sounds and visual events.

Of course, the film is not sentient. It possesses no mind of its own. All significance and purpose ascribed to sounds are endowed defined by the listener / viewer who projects themselves into their own individual experience of the film. As Christian Metz stated, “'denoted reality' [is] one that 'comes only from within us, from the projections and identifications that are mixed with our perceptions of the film" (Metz 1974 quoted in Winters 2010: 226-7). This phenomenological perspective denies the object as a discrete entity and instead positions perception / interpretation as the most significant. As Daniel Yacavone asserts "it is the [audience member] who perceptually and imaginatively actualises this inescapably referential level of a film on the basis of the prior

\footnotetext{
11 'the question becomes whether [a given cue] contributes to generating, or at a minimum, even more firmly grounds, a fictional truth in the scene which it accompanies' (Levinson 1996: 260).

12 "Whereas well-executed sound effects help make a story seem credible, sound affect helps tell the story" (Wizerzbicki 20I6: I57).
} 
knowledge and experience that he or she brings to it, including that of what is and is not fictional (even if this may not always be certain or clear-cut)" (Yacavone 2012: 29).

If the reading of mimesis (and diegesis) lies not in the characteristics of the sound itself but within the listener this requires a transition from striated and distanced observation, to the smooth engaged and material experience of the audiovisual phemomenon. Nicholas Reyland invokes Edward T. Cone to describe this potential for expression:

"Perceivers enact interpretations in response to the traces of what Cone (1982) called, $[\ldots]$ a text's 'expressive potential': the wide but not unrestricted range of interpretative possibilities created by a composition's play of structural and expressive, congeneric and extrageneric elements. As part of that performative process, listeners explore tensions between passionately resisting and passively succumbing to the pretexts, contexts, and subtexts of a text's narrative or other symbolic content. Narrative discourses, after all, are never complete discursive worlds. Stories, for instance, do not exist: they are but briefly held, like a spectral partner, when individuals dance through the architecture of a narrative's discourse." (Reyland 2012: 62).

In this context the materials of the work guide the audience by constructing a framework of representation built upon cultural and perceptual norms in order to frame the interpretative potential of the work. These potentials might be explicit, recognisable architectures or common themes, or they may be implicit, embeded within the materials of the work as characteristics within the structure of larger objects or events.

Embracing subjectivity opens up new possibilities and perspectives for conceptualising the roles and action of film sound, attending to the result of the perceived object as opposed to some false imagined artefact.

In order to do so we accept the following:

a) The film cannot be considered as an object independent from perception, it cannot be studied in isolation from its audience.

b) All elements of the film, including all sounds and the visuals within the film, contribute to the expressive potential of the audiovisual experience, presenting cues from which the audience will build their interpretation. 
c) Reality and abstraction are not absolute and must be considered in relation to the audiences past experiences of both past film worlds and their own reality. Therefore, these can no longer be used as a means to classify and describe the function of sound.

d) Sounds must not be considered as pure signifiers, but as physical events with concrete materialities, the characteristics of which play a vital part in contributing to their expressive potential (b).

The following section elaborates how these approaches were applied in practice to the creation of a soundtrack for the short film coccolith, exploring select aspects of the soundtrack which are constructed around increasingly subtle manipulation of sonic mimesis in order to construct filmic diegesis.

\section{Case Study - coccolith (20I7) - site of action research.}

coccolith is a short film directed by Christopher Brown. The project was conceived around and shot in the Ramsgate tunnels in Kent, UK. A subterranean network of underground passageways that have a diverse history, indissolubly linked with the history of this maritime port city.

The film project served as a site of action research within which creative practice was applied in order to interrogate conventional notions, and terminologies, of filmic realism and diegesis. Within the sonic domain, the goal was to investigate the construction of diegesis through the use of mimetic and abstracted sonic materials and to apply electroacoustic approaches within the films soundtrack, investigating the affective potentials of sound.

Whilst most of the soundtrack was developed in the post-production phase, original concepts were developed in pre-production through dialogue with the director and the cinematographer. One of the key aims was to evoke an impression of the tunnel space, with the narrow tunnel passageways limiting the options for cinematography, it thus fell to the sound to elucidate the expanse of the tunnels through that articulation of off-screen space and to unify disparate characters, scenes and contexts.

\section{Acoustic Horizon and Filtering}

Constructing diegesis from the mimetic, without suspending the impression of the "real" world of the film, necessitated the extension of sound based upon natural physical principals. Our lived experience conditions us to accept, whether consciously or not, the operation and transformation 
of sound according to the acoustic properties of a space as well as the relative operation and disposition of the sound source and us as listener.13

Moulding the mimetic can extend and manipulate the impression of space and activity, shifting perspectives and guiding perception but without explicitly drawing attention to its action. As Winters highlights, "the presence of music in the narrative space of the film [...] is an indicator that the universe in which the events we are watching takes place is not real" (Winters 2010: 230). The absence of this implies an almost documentary aesthetic of realism with the mimetic materials in coccolith drawing the audience forward into the filmic experience.

coccolith's second scene (Clip One) [1:18-2:08] provides a transition from the external world into the tunnel spaces. Just as the soft light on the promenade is replaced by the harsh synthetic glare of the tunnel lights, so too does the soundtrack jar, with the organic flow of the waves overpowered by a rigid and static electronic buzzing which asserts itself into the foreground. This new sound demarcates the change in location but, more importantly, its electronic timbre and rigid character draws attention to the artificial man-made nature of the concrete stairwell with its harsh lighting, creating an inflexible and uncomfortable space. Within and against this overbearing space, the tentative steps of Liam's character provide a more organic and oscillating motion (echoing the rhythmic movements of the crashing waves in the preceding scene). The acoustic frame is more tightly bound, with the wide and modulating panning of the crashing waves replaced with the imposed buzzing sound panned to the mid-left and static; the stereo space is collapsed and narrowed, implying the claustrophobic. The roar of the ocean does remain, but filtered so that only the lower frequencies remain. This effect both emulates the physical realities of distance from a sound source - higher frequencies are more readily absorbed over time so only the lower frequencies project themselves over longer distances - but it also serves to limit spectral space, shifting from the wide broadband and open noise of the promenade to a limited and bounded frame of the tunnel. The cutoff frequency of the low pass filter gradually descends articulating Liam's descent into the tunnel, away from the outside world and - as even the electronic buzzing of "the lights" fade - into a deep introspective space. The soundscape collapses into an enveloping acousmatic rumble, an amorphous signifier of expanse, darkness and the unknown.

The spectromorphological transformations in this short excerpt are derived from mimetic "real world" acoustic effects but extended and articulated for dramatic effect. They are not simply objective but very much subjective, articulating the trajectory of the character and the collapse of

\footnotetext{
${ }^{13}$ Such principals can also be inferred or constructed within the discourse of the film, as they are within the opening sequences of Gravity.
} 
the acoustic space from the wide open external location to the enclosed space of the tunnel and finally the internal space of the character himself.

Manipulation and extension of the soundscape drives the film's diegesis through transformation of the acoustic horizon. They are not explicitly foregrounded but their transformation drives the audiovisual space of the film. In doing so they convey the unseen and fluidly evolving through manipulation of levels to embody the diegetic impression of descent, enclosure and internalisation.

The process of filtering is one of the most common and fundamental audio transformations, often used to morph between subjective states in film. A classic filtering trope is the gesture of the radio broadcast transitioning from narrow band filtered state of the 'tinny' mimetic radio into the envelopment of full range unfiltered underscore. This trope operates in the inverse to the previous example from coccolith, with spectral space opening out rather than collapsing. But both are key diegetic actions. Under the traditional literary framing, this gesture might be described as crossing the diegetic / nondiegetic divide, moving from inside the world of the film to external commentary of a detached narrative layer. But it is the gesture of this transformation and the character of the music itself which conveys the narrative thrust of the diegesis. The expansion of the acoustic horizon renders the notion of freedom that the car affords in delimiting the character's horizons, moving from narrow scope to the wide open road. It's connection to the characters through its initial physical proximity conveys all of the benefits of its acousmtization onto them (increased power and mastery of the scene (Chion 2009: 465)), it cannot convey this by being external to the diegesis, but precisely because it exists within the diegesis, an indissoluble element. The change which does occur is the music's shift to the acousmatic as it becomes detached from its perceived source. In doing so it increases the dynamism of multimedia interaction, shifting from, what Nicholas Cook would describe as, a relationship of conformance to contest (Cook 1998: 98), with an attendant increase in value added. The loss of its source bond is a key part of its gain in power, moving from being contained by an apparent source to enveloping the whole scene, shifting to acousmêtre (Chion 1994: 221).

As the waves in coccolith become filtered, the sounds lose their connection to a concrete implied source, becoming squeezed and extruded into to an enveloping low frequency rumble. Holly Rogers describes this process as sonic elongation which "can lead us deep into the heart of the fiction, generating moments of intense interiority through the gradual dislocation of sound from image.” (Rogers 2018: 4) 
Filtering transforms the soundscape providing diegetic gestures, as sounds transition from mimetic to abstract, detaching themselves from implied sources and shifting fluidly into alternative relationships with the visual image and other sonic materials. The gestural shapes articulate archetypal forms, common energy-motion trajectories that, when combined, project a particular pattern of development ${ }^{14}$. Both sound and music within this context can be described as "entirely integral to the troping that shapes the narrative development, not an 'illustrative' accompaniment to it" (Davis 2012: 16).

Therefore, in moulding the acoustic horizon and shifting the boundaries of acoustic space, the audience are directed towards certain interpretations of the scene built upon both prior experience of this trope in other filmic contexts and their acoustic experiences within the world. As the scene progresses, there is no schism within our perception of reality - one perceived reality is merely morphed into another. The sonic elements do not transition between layers of commentary, rather the trajectory of the gesture directs our experience of the scene and frames our relationship with the character Liam.

\section{Tactile sound - Mimesis and Proximity}

Perhaps ninety percent of the sounds that might be attributed to the character Liam were recorded during the post-production phase of the project. Breathing, fabric movements, footsteps, torch clicks were all carefully chosen and layered in post-production to enhance the physical and tactile impressions of the character. Using close microphone positions to capture the recordings, sounds were designed to create an intimate impression where the audience connected to the character through the impression of sonic proximity. The listener is both placed within a highly personal sonic space (in close proximity to that heard), and the timbres of these sounds also provide a connection to the physical and tactile. When heard in the context of the image, these sounds convey their character into the frame, modulating it, constructing the space of the film, both mimetic and diegetic (in the sense of telling the story).

When Liam loses these sounds he begins his transition out of the "real" material space of the tunnel and into the "abstract" dream space. Indeed, the mysterious character of the Smoking Man is framed by the relative lack of sound associated with him. When the two men meet [5:47] the crunch of Liam's footsteps and the squeezing and strain of his fabric articulate his concrete reality, while the Smoking Man is silent. The intensified nature of these mimetic sounds also articulate the

\footnotetext{
${ }^{14}$ See Denis Smalley's writings on Spectromorphology for more detail: Smalley 1986, Smalley 1997.
} 
dramatic, with the creaking and cracking strain of fabric sonically representing the tension of nervous intimacy as Liam moves to kiss the Smoking Man during their encounter. When the two men appear again together in the final dancing scene [13:3I] both have surrendered themselves to the tunnel, their lethargic movement perhaps implies this, but they also no longer possess any of their own mimetic sounds, no breathing, no fabric, no footsteps. They are completely unanchored, enveloped by the dreamy electronic music that fills the space.

Therefore, we can understand that these sounds perform a function beyond simple signposting. These mimetic sounds are not just the sounds of the characters and their costumes. They embody both tactile impressions of the characters within the space and also perform functions in the filmic narrative conveying mood and tension (ideas that might traditionally be classified as roles associated with non-diegetic sound). They are part of the fabric of the scene itself and key components within the construction of the diegesis.

\section{Reverberation \& acoustic space}

A mimetic marker that accompanies all sound is that of reverberation. When sounds radiate from a source they do so in all directions, some of these radiated sound waves travel directly to the listener, while others intersect with surrounding surfaces and are either absorbed or reflected. On their journey these reflected sounds become altered by their encounters, perhaps loosing certain frequencies and certainly arriving from a different direction. Further, because these reflected sounds have travelled a longer distance to reach the listener they are delayed from the direct sound. Reverberation is a physical characteristic that exists in all spaces, it is the effect which makes an empty room ring, and a furnished one dull, we make use of it as a sonic cue to gather information about the kind of space in which we are located. While we might not notice the action of reverberation in our daily lives it is always there informing our understanding of space and location. Miguel Mera highlights that reverb also forms a powerful rhetorical tool in film sound, "[the] extensive use of reverb in all channels, [is] a rhetorical device that signals that the scene does not represent reality" (Mera 2016: 101).

The film script called for a tonal musical accompaniment to the 'Disco Woman' character, which afforded an opportunity to explicitly explore the classic notion of the diegetic / non-diegetic divide and to subvert audience expectations. This singular use of tonal music within the film might be thought of as signifying the very filmic unreality that the opening scenes of the film have sought to obfuscate, to highlight a moment of fantasy within the concrete realities of the tunnel. However, by applying varying types and levels of reverberation it became possible to position the music in a liminal state between underscore and mimesis. To draw the audience to question the relationship 
of the music to the characters and, through its articulation of space to drive the diegesis forwards through its modulation and transition. The application of reverb in this context utilises the compositional potentials embodied within the impression of space.

During the production process, impulse response sweeps of the tunnel spaces were captured. These tones ring out in the space and when recorded form a document of the reverberant characteristics of that physical space. Using software a virtual approximation of the room acoustics can then be developed. ${ }^{15}$ This subsequently enables any sound to appear as if it were sounding within the physical space of the location, often used, for example, to blend Foley footsteps or rerecorded dialogue in with location recorded sound. Therefore, applied to this tonal musical excerpt, a tension is activated between the traditional conception of underscore as distanced from the mimetic, and the character of this music coloured with the acoustic space of the tunnels.

The acousmatic nature of the sound source affords fluidity in its articulation. It first emerges through a slow fade in with high levels of reverberation and little direct sound. Distant and reverberant this sound might initially be considered a signifier of the unreal (as set out by Mera above) but the acoustic character of the reverberation, matching the acoustic character of the tunnel spaces, anchors this sound within the physical tunnel spaces. As the sequence progresses the volume level of the dry and unprocessed sound increases. This brings the music towards a more conventional abstract position, with the sounds occupying an acoustic space distinct from that of the tunnels. However, the music is never fully able to make the transition into an alternative acoustic space because the reverb is always present, even if subtle. Indeed, when we see Liam exit the tunnel we hear the filter on the reverb lift and the acoustic space expand as he steps out into the tunnel. The point of audition is therefore implied at this moment as resting with the character Liam. And as he moves forwards and the balance of dry and reverberant sound again shifts, the result is to bring the audience along with the character, positioning all within the same space, not to leap from the world of the tunnel.

The flexibility in manipulating acoustic space masks any explicit distancing of the music from the world of the film, the changes in reverberation quality allow the music to move within a liminal space - floating between the space of the tunnel and an all-enveloping soundscape. Acoustic space and reverberation therefore becomes a key parameter in the consideration of sound in film.

\footnotetext{
${ }^{15}$ Many tools are available for this kind of practice. The project in question utilised Altiverb XL by AudioEase.
} 


\section{Mimetic to Diegetic}

These three examples elaborate the diegetic power of ever more-subtle mimetic properties of sound. The acoustic horizon, material proximity and reverberant space are all parameters of sound which exist within the physical world and thus our experience of them is very common and their articulation in film is fundamentally mimetic. But far from being neutral or transparent markers of some abstract "real", they possess very tangible potential to direct and articulate narrative and story. Subjectivity opens up the possibility for the audience to interpret the same scene in a variety of ways, and the audience may shift their listening mode, choosing to modulate their interpretation of the sounds present. However, the combination and articulation of sounds will guide and direct the listener toward more specific interpretations. It is no longer a case of whether a sound might be heard as objective or subjective; additive or narrative; an effect or an affect; diegetic or mimetic. But about how the combinations and complexes of these sounds, evoke and elaborate a hyperreality that is the world of film, into which audience's project and immerse themselves.

\section{Conclusion}

All sounds in film have the potential to convey meaning and to contribute to narrative structure. They do so in a variety of imbricated ways: timbral, spatial, gestural, semiotic, contrapuntal.

Traditional hierarchical analyses of film sound often focus upon segregated elements of the soundtrack - musical underscore in isolation from "diegetic" sound, "diegetic" sound as mere marker of filmic reality. In such readings the musical underscore is reframed as an abstract signifier (denying its materiality and its ability to convey diegetic action); while sound effects are interpreted as objective signifiers of source cause (with a fixation upon implied reality). Such stratified approaches to soundtrack analysis actively mask the wider expressive potentials of sound in constructing filmic narrative, prioritising specific types of sound over others and obfuscating the potential for deeply entwined counterpoint between the various sonic materials and the image. And yet, every sound in a film modulates the diegesis, directing audience attention to specific elements or objects within the world of the film and embodying textural, gestural or spatial properties which convey meaning through the materiality of the sound. Absences of sound can be just as significant, subverting expectation or merely directing attention away from aspects of cinematic action that are regarded as superfluous to intended narrative. 
With contemporary filmmaking approaches adopting ever more fluid approaches to soundtrack design/composition it is essential that approaches for conceptualising and discussing soundtracks are suitable for the task. It is vital to embrace an understanding of film as fundamentally unreal and to appreciate that all sounds (both mimetic and abstract) are applied for diegetic purpose.

"The sound does not serve, it is." (Chion 2010: 167)

In seeking to understand the role and action of sound in film, our attention should not be directed not to some absolute objective real represented by the "filmworld" but to the experience of the film by the audience, and how the combination of all sounds (and images) work to suggest particular interpretations through their articulation and modulation. 


\section{References}

Altman, Rick, (1980) 'Moving Lips: Cinema as Ventriloquism', Yale French Studies: Special Issue Cinema/Sound, 60, 1980, pp. 67-79.

Birtwistle, A. (2010) Cinesonica: Sounding film and video. Manchester University Press.

Birtwistle, A. (2016) Electroacoustic Composition and the British Documentary Tradition. IN: Greene and Kulezic-Wilson (eds.) The Palgrave Handbook of Sound Design and Music in Screen Media. Macmillan Publishers, London. (pp. 387-402).

Bouzereau, L. (2003) Sound of Indiana Jones [Film] IN: The Adventures of Indiana Jones Complete DVD Movie Collection - Bonus Materials [DVD] Paramount. [2:08-3:00]

Chion, M. (1994) Audio Vision: sound on Screen. Columbia University Press.

Chion, M. (2009) Film, A Sound Art. (trans.) Claudia Gorbman. Columbia University Press.

Chion, M. (20I2) Guide to Sound Objects. (trans. John Dack and Christine North).

Clarke, D.; Clarke, E. (20II) Music and Consciousness - Philosophical, psychological and cultural perspectives. Oxford, OUP.

coccolith [FILM] dir. Christopher Brown. Unpublished.

Coëgnarts, M.; Kravanja, P. (20I5) Embodied Cognition and Cinema. Leuven, Leuven University Press.

Cone, E. T. (1982) Schubert's Promisory Note: an exercise in musical hermeneutics. 19th Century Music 5(3) pp.233-4I

Cook, N. (1998) Analysing Musical Multimedia. Oxford, OUP.

Cox, A. (2016) Music and Embodied Cognition - Listening, Moving, Feeling \& Thinking. Bloomington, Indianna University Press.

Davis, N. (2012) Inside/Outside the Klein Bottle: Music in Narrative Film, Intrusive and Integral. Music Sound and Moving Image, 6(I). Liverpool University Press. Pp. 9-19

D’Escrivan, J. (2007) Imaginary Listening. IN Proceedings of EMS 2007, Leicester.

Dunkirk [FILM] dir. Christopher Nolan. Warner Bros. Pictures. 2017

Eisenstein, S.; Pudovkin, V.i.; Alexandrov, G.V. (1928) A statement (on film sound) (trans Jay Leyda). IN Film Sound: Theory and Practice. Weis and Belton (ed.) Columbia University Press.

Emmerson, S. (2007) Living Electronic Music. London: Ashgate.

Gorbman, C. (1987) Unheard Melodies: Narrative Film Music. Indiana University Press.

Gravity [FILM] dir. Alfonso Currón. Warner Bros. Pictures. 2013

Hill, A. (2017) Listening for Context: Interpretation, Abstraction and the Real. Organised Sound, 22(I) Cambridge University Press PP. II-I9.

Ingold, T. (2000) Perception of the Environment. New York: Routledge

Kassabian, A. (200I) Hearing Film: Tracking Identifications in Contemporary Hollywood Film Music. London: Routledge.

Kassabian, A (2007) Hearing as a Contact Sense?

Kramer, L.; Goldmark, D.; Leppert, R. (2007) Beyond the Soundtrack: Representing Music in Cinema. University of California Press: Berkley. 
Levinson, Jerrold (1996) 'Film Music and Narrative Agency' in David Bordwell \& Noël Carroll (eds) Post-Theory: Reconstructing Film Studies, Madison, WI, and London: University of Wisconsin Press, pp. 248-82

Landy, L. (2010) Understanding the Art of Sound Organisation. MIT Press:

Manning, P. (2004) Electronic and Computer Music. Oxford University Press: Oxford.

Miguel, M. (2016) Towards 3-D sound: Spatial Prescence and the Space Vaccum. IN The Palgrave Handbook of Sound Design and Music in Screen Media: Integrated Soundtracks. Greene and Kulezic-Wilson (eds.) London: Palgrave Macmillan. Pp. 9I-II2

Norman, Katharine 1994. "Telling Tales”. Contemporary Music Review. 10(2): 103-109.

Norman, K. 1996. A Poetry of Reality: Composing with Recorded Sound. Contemporary Music Review I5(I-2): I-57.

Varese, E. (2004) The Liberation of Sound. In Cox and Warner (ed.s) Audio Culture. Continuum Press

Schaeffer, p. (1966) Traité des objets musicaux. Paris: Le Seuil.

Schaeffer, P. (20/2) In Search of a Concrete Music. John Dack \& Christine North (trans.), University of California Press: London.

Smalley, D. (1986) Spectro-morphology and Structuring Processes. In S. Emmerson (ed.) The Language of Electroacoustic Music. Basingstoke: Macmillan Press.

Raiders of the Lost Ark [FILM] dir. Steven Spielberg. Paramount Pictures. 198I

Reyland, N. (2012) The beginnings of a beautiful friendship?: Music Narratology and Screen Music Studies. Music Sound and Moving Image, 6(I). Liverpool University Press. Pp. 55-7I

Robyn. Stilwell, R. 2007 - the fantastical gap between Diegetic and Non Diegetic, in Beyond the Soundtrack, ed. Daniel Goldmark, Lawrence Kramer and Richard Leppert (Berkley; Los Angeles: University of California Press, 2007)

Rogers, H. (2019) "Sonic Elongation and Sonic Aporia: Soundscape Composition in Film", in Carlo Cenciarelli (ed), The Oxford Handbook of Cinematic Listening (NY: OUP) forthcoming 2019.

Russolo, L (1913) The Art of Noises: Futurist Manifesto. IN Audio Cultures Cox and Warner (ed.) New York: Continuum.

Staiger, Janet. 1992. Interpreting Films. Studies in the Historical Reception of American Cinema. Princeton: Princeton University Press.

Stillwell, R. (2007) The fantastical gap between diegetic and non-diegetic. IN Beyond the Soundtrack: Representing Music in Cinema, Kramer, Goldmark and Leppert (eds.) Berkley: University of California Press. Pp. I84-202.

Stowell, D. (20II) Scheduling and Composing with Risset Eternal Accelerando Rhythms. IN: Proceedings of International Computer Music Conference, Huddersfield.

Smith, J. (20/3) The Sound of Intensified Continuity. IN: The Oxford Handbook of New Audiovisual Aesthetics. Richardson, Gorbman, Vernalis (ed.). London: Oxford University Press.

Tsai, Ming-Liang. 2003. Goodbye, Dragon Inn. Taiwan: Wellspring Media.

Yacavone, D. (2012) Spaces, Gaps and Levels: From the diegetic to the Aesthetic in Film Theory. Music Sound and the Moving Image. 6(I). Liverpool University Press. Pp. 2I-37 
Winters, B. (20I0) THE NON-DIEGETIC FALLACY: FILM, MUSIC, AND NARRATIVE SPACE. Music \& Letters, Vol. 9I No. 2. Oxford University Press: Oxford

Wizerzbicki, J. (2016) Sound Effects / Sound Affects: "Meaningful" Noise in the Cinema. IN The Palgrave Handbook of Sound Design and Music in Screen Media: Integrated Soundtracks. Greene and Kulezic-Wilson (eds.) London: Palgrave Macmillan. Pp.I53-I68 